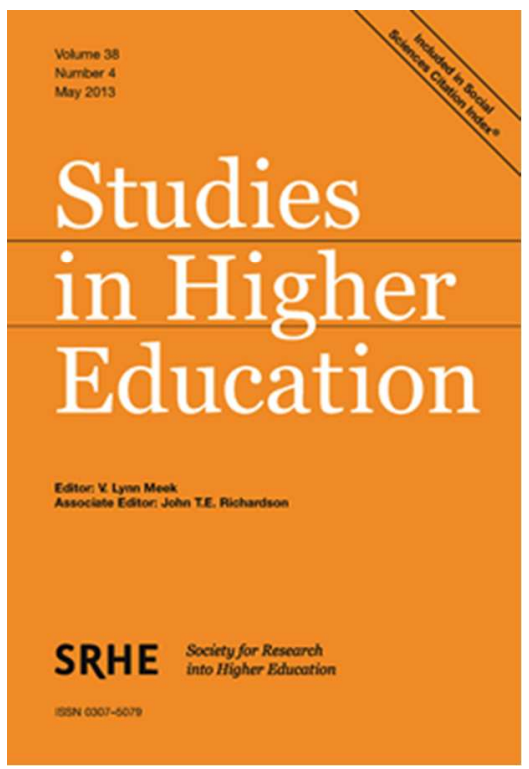

\title{
A best-practice model for integrating interdisciplinarity into the \\ Higher Education student experience
}

\begin{tabular}{|r|l|}
\hline Journal: & Studies in Higher Education \\
\hline Manuscript ID & CSHE-2016-0446.R2 \\
\hline Manuscript Type: & Article \\
\hline Keywords: & $\begin{array}{l}\text { Interdisciplinarity, Collaborative learning, Role of Higher Education, } \\
\text { interdisciplinary projects, Teaching and Learning }\end{array}$ \\
\hline
\end{tabular}

\section{SCHOLARONE"}

Manuscripts 
Response to comments from reviewers

\begin{tabular}{|l|l|}
\hline $\begin{array}{l}\text { Reviewer } \\
\text { Comment }\end{array}$ & Response \\
\hline $\begin{array}{l}\text { Please review use of the word 'wicked' and } \\
\text { other words in quote marks without an } \\
\text { accompanying reference; these a somewhat } \\
\text { distracting. }\end{array}$ & $\begin{array}{l}\text { Wicked - has been re-considered and reduced } \\
\text { in frequency. } \\
\text { Throughout the document the use of single and } \\
\text { double quotation marks has been revised. }\end{array}$ \\
\hline $\begin{array}{l}\text { Because there is no claim of generalizability, } \\
\text { the HIM should not be presented definitively } \\
\text { (i.e. 'the' model). }\end{array}$ & $\begin{array}{l}\text { The references to 'the HIM' have been changed } \\
\text { to the proposed/emergent HIM model } \\
\text { throughout. }\end{array}$ \\
\hline $\begin{array}{l}\text { The abstract and conclusions should note the } \\
\text { key research limitations, and the } \\
\text { recommendations should reflect these } \\
\text { accordingly. }\end{array}$ & $\begin{array}{l}\text { Abstract, conclusion and recommendations } \\
\text { have all been revised to more extensively note } \\
\text { the study's key research limitations. }\end{array}$ \\
\hline $\begin{array}{l}\text { The end of the Introduction section is } \\
\text { unnecessarily confusing. What is the } \\
\text { 'qualitative study which explored two research } \\
\text { questions?' }\end{array}$ & $\begin{array}{l}\text { The third paragraph of the introduction has } \\
\text { been substantively revised to clarify the aim, } \\
\text { the relevance of figure } 1 \text { and the study's } \\
\text { methodology. }\end{array}$ \\
\hline $\begin{array}{l}\text { What is the aim of this paper and where does } \\
\text { Figure } 1 \text { fit in? Could you please ensure these } \\
\text { questions/ points are addressed. }\end{array}$ & $\begin{array}{l}\text { A clear statement has been added at the end of } \\
\text { the third paragraph, of the introduction, with } \\
\text { reference to figure 1, which has been re- } \\
\text { located to appear earlier in the paper. }\end{array}$ \\
\hline
\end{tabular}




\title{
A best-practice model for integrating interdisciplinarity into the
}

\author{
higher education student experience
}

\begin{abstract}
Today's global society creates an environment characterised by complex problems, solutions to which require transcendence of traditional discipline-based boundaries, and new forms of knowledge-sharing. Higher education (HE) has a central role in interdisciplinary knowledge creation and dissemination, reinforced by funding councils, professional bodies and government policy. That notwithstanding, there is currently no recognised best-practice approach to interdisciplinary working in UK HE institutes. The aim of this paper is to develop a best-practice model to facilitate interdisciplinarity within the UK HE sector, focusing on teaching and learning (T\&L) and the student learning experience. Based on the results of an exploratory and empirical enquiry a HE Interdisciplinary Model of best-practice (HIM) is proposed. HIM is informed by the development of four themes and six ensuing enablers from a synthesis of perceived barriers, possible facilitators and potential solutions to interdisciplinarity within UK HE. However, further research is necessary to validate the proposed model.
\end{abstract}

Keywords: collaborative learning, higher education, interdisciplinarity, interdisciplinary, teaching and learning.

\section{Introduction}

In the modern, global, landscape we are faced with many complex challenges requiring novel solutions. It is recognised that innovative and sustainable approaches to addressing today's, and tomorrow's global challenges reach far beyond the boundaries of a single academic discipline or methodological approach and require new ways of working (Stember 1991; Jahn et al. 2012; McLeish and Strang 2014). This wicked, messy context (Jordan et al. 2014), with challenges such as sustainable cities and global gender equality (United Nations 2015) demands a shattering of traditional disciplinary boundaries and creates a strong rationale for embedding interdisciplinarity into the HE student learning experience. It is argued here that HE graduates, in order to be part of the solution and, therefore, employable, need to be prepared for such messiness and complexity through the integration of interdisciplinary problem solving within their learning experience (Stember 1991; Walsh and Kahn 2010; Marcketti and Karpova, 2014). This is supported by UK government policy-makers, funding councils and professional bodies (RAE 2012; McLeish and Strang 2014; BIS 2016).

There are continued challenges to the realisation of interdisciplinarity within UK HE institutional settings. For example, each discipline has developed its own goals for academic and research endeavours, which has led to a parochial approach to both teaching and research development (Stember 1991; McLeish and Strang 2014). It is in this context that this paper advocates a joined-up approach in order to overcome institutional, discipline-based and 
individual barriers to knowledge production and innovation. It is proposed that a culture of integration across disciplines will benefit learners, academics and institutions and produce better solutions to complex social problems.

This paper aims to develop a possible best practice model for interdisciplinary working within a UK HE T\&L context - a potential HE Interdisciplinary Model (HIM) is proffered. This proposed model emerged following an exploratory study utilising an expert panel and semi-structured interviews, as discussed in the methodology section of this paper (Figure 1). Two research questions were explored: firstly if the tenets of interdisciplinary collaboration are accepted as valuable to innovation, employability and intellectual capacity building, what are the barriers to HE Institutions embedding interdisciplinarity as mainstream within the student learning experience? Secondly; what are the key facilitators and potential solutions that will maximise the successful integration of interdisciplinary collaboration into the student learning experience?

The context for this research and the strategic imperative for interdisciplinarity will be further developed in the background section, followed by details of methodology and the approach to data analysis leading to the development of the proposed HIM model (Figure 2).

Figure 1 near here

\section{Background}

Interdisciplinary research is acknowledged as having great potential to break through complex social problems and foster innovation, with literature highlighting how many of the most exciting developments and solutions to global challenges cross traditional disciplinary boundaries (Kast et al. 1970; Stember 1991; Elsevier 2015).

Elsevier (2015) summarised the benefits of interdisciplinary approaches under five categories: providing sustainable solutions to wicked problems, refining current research problems at their interface, providing stimulus to the discipline area, challenging current knowledge and understanding of the world, and developing new methodical approaches. However, other studies identify significant challenges and barriers relating to interdisciplinary collaboration. Lawrence and Lorsch (1967) suggested that states of differentiation and integration within an organisation are antagonistic; greater differentiation among organisational participants creates more challenges in achieving true integration, with a logical conclusion being that attempts to achieve integration might require less differentiation/departmentalisation. Indeed, within HE, academic disciplines serve to construct identity as an academic community and a sense of belonging; they align methodologies and discipline epistemology and, not surprisingly, faculties are often reluctant to cross-fertilize (Stember 1991).

Interdisciplinary collaborations call for the open exchange of ideas, challenging the personal and institutional boundaries acting to maintain a sense of ownership and authority over territories of knowledge. It is of no surprise that an interdisciplinary agenda can generate both passionate enthusiasm and also defensive opposition within large complex organisations such as HE Institutions. Nevertheless, funding council priorities and agendas increasingly require collaboration or interdisciplinarity, thus pushing universities towards a partnership based 
approach to research (RAE 2012; McLeish and Strang 2014; DC 2015; BIS 2016). Moreover, interdisciplinarity and collaboration is itself potentially more lucrative to UK HE, being associated with higher levels of patent applications, stronger relationships with industry and a greater chance of new knowledge to solve wicked problems (Elsevier 2015; United Nations, 2015).

\section{Interdisciplinarity: $T \& L$}

Whilst there are several possible interpretations of the fundamental role of universities, one enduring concept is that of universities as institutions for the creation and dissemination of knowledge, producing graduates who have a genuine commitment to making the world a better place (Kast et al. 1970), and of being significant players in civil society (Watson 2014). Clark (2014), for example, referred to universities as centres of excellence able to unlock talent and potential, and to drive economic growth, which suggests new ways of working in our complex and uncertain world. Interdisciplinarity is widely purported to be the new mode of knowledge production, focusing on building intellectual capacity and contributing to social change (Jahn et al. 2012; Elsevier 2015).

The call for an interdisciplinary learning experience is reinforced by growing emphasis on graduate employability and transferable graduate skills (Marcketti and Karpova 2014). The government white paper (HE: success as a knowledge economy) stated that HE is no longer for the elite; new reforms will focus on technical skills and routes into key occupations (BIS, 2016). Indeed, in a metrics-driven UK HE context, graduate employability is a key indicator of course and university success. To raise levels of graduate employability, several commentators have devised lists of requisite skills to be developed, including team working, problem solving and communication (Hawley 2005; CBI 2009; Power 2010; CIPD 2016), all of which benefit from working across discipline boundaries. Marcketti and Karpova's (2014) study highlighted the value of working collaboratively with industry from the students' perspective, concluding that students appreciated the opportunity of co-working to develop problem solving skills in a real world environment with their peers. De Hei et al. (2015) recognised that the effectiveness of collaborative learning in HE depends primarily on core aspects being designed into the learning experience, including: interdependence, accountability and interaction. Stember's (1991) work proposed similar important attributes for successful interdisciplinary team working, predominantly focusing on the sense of belonging. In successful interdisciplinary teams it has been argued that the ability to balance differentiation and integration is essential, with $\mathrm{HE}$ students requiring an element of metacognition in order to establish ground rules, explicating and resolving methodological differences (Stember 1991).

In summary, there is evidence to suggest that UK HE Institutions, their research and their students, would benefit from interdisciplinary working. However, little is currently known about the barriers and facilitators to such, particularly related to HE student learning, and potential sustainable solutions.

\section{Methodology}


Given the novelty of the topic and research focus, this is an exploratory study utilising an expert panel and semi-structured interviews (see Figure 1 for the research design). Due to the paucity of prior research in this area a sample of experienced, senior T\&L leaders were used to explore perceived barriers, possible facilitators and potential solutions to embedding interdisciplinary into HE T\&L. This expert panel comprised a purposive sample of six participants, each of whom was selected, as suggested by Saunders (in Symon and Cassell, 2012), as a particularly informative participant, able to facilitate achievement of the research aim. Thus, an expert panel, typically adopted in research when specialized input is required and highly suited to small scale exploratory studies such as this, was used. Participants were selected according to the criteria in Table 1. Adopting an interpretivist perspective, views of the expert panel were sought in order to develop a deeper understanding of factors relating to interdisciplinary working. The participants interviewed for this study each had sufficient rich and detailed knowledge of the sector to inform the research aim and facilitate focus on the research questions identified above. The sample was also convenience based, with the final expert panel being invited to participate based on (perceived) expert knowledge, availability and close proximity to the researcher's main location, the latter primarily governed by the unavoidable time constraints ( 1 month) of the data collection process (Table 1).

Table 1 near here

A total of six semi-structured interviews were conducted, with representatives from two universities in the North of England and one participant from the commercial design sector. Individual responses have been coded to protect identity of the individual; however, participants occupying the following roles were included: University Deputy-ViceChancellor, University Dean, University Pro-Vice-Chancellor, Chairman Global Design Consultancy (Professor of Innovation), Professor of Innovation, and University Head of Enterprise. A small sample such as this is perfectly acceptable in an exploratory study of this nature (Patton 2002; Reeves and Hedberg 2003), with deliberate selection of participants to better understand a novel or emergent phenomenon (Lincoln and Guba 1985; Robson 2011). Moreover, as noted by Guest et al. (2006) and Robson (2011), a sample of this size is sufficient where theoretical saturation has been reached in a study involving non-probabilistic sampling and qualitative analysis, as in this study. Each interview lasted for at least an hour, providing time to obtain rich and detailed data. A pilot study with one participant was conducted, resulting in a minor change of phrasing for clarification (this interview is included in the main sample due to quality and richness of data obtained).

Interviews were adopted in this research to facilitate emergent discourse around the broad theme of interdisciplinarity, since it would have been impossible to identify very detailed a priori models or parameters of interdisciplinary working within HE T\&L. Broad topics for conversation were identified, reflecting general themes indicated through the literature review. This very loose structuring of interviews would enable the researchers to use probe questions and develop emergent conversation in line with responses on the day and reflecting the knowledge and prior experience of the participant. Specific themes to be discussed were: external drivers for collaboration, value of interdisciplinarity, barriers/facilitators and solutions/optimum structures, all in the context of UK HE. 
A three-stage process was employed: extant literature was analysed for gaps in knowledge, areas of controversy or conflicting views on factors which impact the implementation of strategy and key policy influencers relating to embedding interdisciplinary collaboration into the student experience. These were then rephrased into 8 main questions and 14 probe questions, all within the remit of 4 broad categories identified above.

Following synthesis and evaluation, the literature highlighted (2) barriers to and (3) facilitators of interdisciplinarity within the HE student learning experience. Table 3 presents a summary of emergent themes from the literature, contextualised in the discussion to follow (literature review: barriers to and facilitators of interdisciplinarity).

\section{Primary Data analysis}

Interview data was transcribed and analysed using a data display and analysis technique to order the data, before the use of open thematic coding to establish emerging themes. A fourstage thematic coding process was used (Miles and Huberman 1994). Initially, open codes were assigned; this was followed by a re-read and the addition of further open codes and subcodes (axial codes); The codes were allocated more general themes to link related information together (category codes) and finally the open codes were ranked in order of frequency. Table 2 presents the analytical strategy which underpins the data analysis and the findings of this research. This primary data was then triangulated with the data obtained from the literature review (Table 3) under the headings of barriers and facilitators/solutions (Table 8).

\section{Table 2 near here}

\section{Ethical consideration and limitations}

Research ethics practice adopted in this study have been consonant with the home institution's code of practice and the Vitae (2015) ethical principles for research. All participants gave informed consent and allowed the interview to be recorded. Limitations of this study include the small sample size, although this was an exploratory inquiry and, as such, no claims are made to generalisability. Moreover, the purposively selected expert panel, whilst generating rich data, cannot be considered statistically representative of the total population. To minimize bias, interview findings are fused with extant literature to arrive at the model in Figure 2, which more extensive studies can proceed to validate prior to wide scale adoption.

\section{Literature review: barriers to and facilitators of interdisciplinarity}

Although interdisciplinarity is increasingly identified as essential, there are conflicting views regarding methods to create conducive research and teaching environments (Table 3). The 
most prevailing facilitator of embedding interdisciplinarity within HE was professional bodies (including funding councils and government bodies), the policies of which are key to driving changes in HE strategy. It was reported in 2014 that the UK Research Councils actively seek to support novel, collaborative approaches to find solutions to complex questions (McLeish and Strang 2014). Elsevier (2015), similarly, recognised collaboration as an underpinning principle of research. In the context of the undergraduate experience, Clark (2014) acknowledged universities as aspiration centres of excellence to unlock talent and potential, and to drive economic growth. More recently, it was stated that new reforms in HE will focus on technical skills and routes into key occupations (BIS 2016). Furthermore, there is a plethora of literature to support collaboration, use of live briefs and the value of problem solving in relation to the HE employability agenda across a broad range of disciplines (Stember 1991; Hawley 2005; CBI 2009; Power 2010; Marcketti and Karpova 2014; CIPD 2016; De Hei et al. 2016). The espoused values of several professional bodies and councils reinforce the superiority of multidisciplinary teams for solving complex challenges (for example, The Royal Academy of Engineering (RAE, 2012) and The Design Council (DC 2015). Thus, using the professional bodies as a key facilitator is essential to a change model for HE sector (see first facilitator, Table 3).

Table 3 near here

Eight interrelated codes (sub-themes) emerged under the facilitator - providing a climate (Table 3). These were strongly related to institutional provision of environments conducive to interdisciplinarity. Stember (1991) and McLeish and Strang (2014) identified a sense of belonging and rewarding atmospheres as key themes. Leadership/leadership challenges was a further prominent code (Miller and McCartan 1990; Jahn et al. 2012; McLeish and Strang 2014 and Elsevier 2015). Both a strong sense of belonging and effective leadership was seen to support interdisciplinarity. Walker (1994) highlighted the significance of creating communities of learning for cross fertilisation, whilst recognising that alignment of discipline epistemology and methodology was essential in terms of providing spaces for the open exchange of ideas. Miller and McCartan (1990), Stember (1991) and McLeish \& Strang (2014) acknowledged the importance of creating space outside departmental politics and a reduction in interdepartmental division. This was closely related to Jahn et al.'s (2012) call for new cultural practices (exchange of cultures) to be established to promote open exchange of ideas.

In terms of reward and the promotion of good practice (final facilitator, Table 3) Mullins, (2007) and Torrington et al. (2014) all recognised the role of talent management and individual recognition (through congenial and rewarding atmospheres) being aligned with interdisciplinary working.

In summary, therefore, the literature provides a strong underpinning for the three key facilitators/solutions identified in Table 3. The above social and institutional logic for interdisciplinarity notwithstanding, progress within the HE sector has been slow, with several proposed barriers or obstacles to interdisciplinary working (Table 3). Whilst reward is recognised as a facilitator, if not aligned with interdisciplinarity it can become a potential 
barrier. For example, Elsevier (2015) highlighted the disparity between interdisciplinary published work and citation impact, which could be a significant barrier to leading scientists, researchers and educators integrating knowledge from their respective fields.

Table 3 highlights a further seven structure/process barriers. McLeish and Strang (2014) suggested that interdisciplinary research goes against the grain of many established systems and processes and for this reason can be problematic in large organisations. This resonates with Kast et al. (1970) and Stember's (1991) prior work which identified the significance of poor organisational structures, administrative processes and discipline ownership/divergent discipline goals as barriers to the growth of interdisciplinary within the HE. It is also recognised that the UK modular structure of curricula based in academic disciplines create barriers and closed-minded/parochial approaches to teaching that are counterproductive to interdisciplinarity (Stember 1991; John et al. 2012; McLeish and Strang 2014; Elsevier 2015). Stember (1991) and McLeish \& Strang (2014) further stated that collaborations challenge the real and perceptual boundaries that function to maintain ownership and authority over territories of knowledge. Lawrence and Lorsch (1967), similarly, found that greater differentiation among organisational participants creates more challenges to achieving true integration. Stember (1991) reinforced this view in terms of alignment and appreciation of differences in preferred methodologies and discipline epistemology. Indeed, McLeish and Strang (2014) went as far as stating that interdisciplinary research requires a complex skill-set which is underdeveloped within HE, providing further underpinning for the value of embedding interdisciplinarity into the student experience to enhance employability.

Table 3 summarises these key barriers and facilitators as identified in the literature. The following section will consider primary data findings, followed by a discussion and presentation of the fusion of primary and secondary data in Table 8 . The derived model (HIM) will then be considered.

\section{Findings}

Primary data was coded using the four stage thematic coding approach identified above. This paper focuses directly on a detailed analysis of three of the established category codes barriers, facilitators, solutions as illustrated in Table 4. This table presents a synthesis of the open and axial codes which were used to construct the overarching category codes. Data analysis revealed that the primary factors ascertained from the open coding constituting the barriers were predominantly related to university regulations (regulations), professional body regulation (PRSB), personal barriers (staff) and practicalities such as logistics of timetables (resources). Further, data suggests that those primary factors constituting the facilitators were predominantly related to institutional culture (culture), staff attitude/ambition (staff), reward/acknowledgement (recognition), faculty culture (structure), and a mix of other factors, including policy/electives/environment/impact (other). Finally, the data revealed that the primary factors constituting the solutions to implementing interdisciplinarity into the student experience were predominantly related to positive narrative (communication), the proposed model (structure) and having influential role models as agents of change (culture change).

Table 4 near here 
Narrative data supporting Table 4 is illustrated with extracts in Table 5 (for barriers category codes), Table 6 (for facilitators category codes) and Table 7 (for solution category codes). Examples of prevailing barriers (Table 5, open codes), were perceived to be institutional regulations, and external regulations from professional bodies (PSRB). Whilst these formed two open-codes, they were strongly related and interpreted here as regulations. However, most of the barriers raised by participants represented individual perceptions rather than absolute restrictions imposed by the regulatory or professional body framework. Other barriers related to resistance from staff and simple logistics such as timetabling/space for interdisicplinary learning. Participant narrative suggested that regulation barriers were easy to overcome, or were more perceived than actual.

Table 5 near here

As highlighted in Table 4 facilitators was the most complex category code, comprising eight, inter-related open codes (culture, staff, recognition, structure, environment, policy, elective, impact). The most prominent open code was culture, with axial coding suggesting the importance of greater alignment with the commercial sector and culture in relation to rewards and targets in particular. This is clearly evident from the extracts highlighted in Table 6 . The second most prominent open code was staff; lower level axial codes included the promotion and cultural aspects of aspirational T\&L in addition to knowledge co-creation. Both open codes culture and staff were related to the third most prominent open code, recognition, encompassing the value of individual and team contributions and the complexity surrounding rewarding individual efforts (Table 6). Other, lower priority, open codes included structure and electives (identifying the need to break down faculty silos), policy and impact that fosters interdisciplinary working and the importance of creating environments (space, buildings and conducive facilities) to ease the transition to an interdisciplinary culture (Table 4).

\section{Table 6 near here}

The final category code in Table 4, solutions, was constructed from the open codes of communication, structure and culture change, with illustrative extracts in Table 7. The open codes within this category were all interrelated: communication, structure and culture change. The extracts in Table 7 highlight a number of factors including: the importance of narrative and an improved flow of communication (communication); an appropriate climate (structure) to facilitate interdisciplinarity; and the reward/promotion of the good practice of academic champions (culture change) in providing sustainable solutions to the implementation of interdisciplinarity into the student experience.

Table 7 near here 


\section{Key barriers, facilitators and solutions: A discussion and synthesis}

Category coding for primary data analysis was separated into barriers, facilitators and solutions (Table 4), with extracts associated with the axial codes presented in Tables 5-7. However, upon further analysis of the data it was clearly evident that there was a degree of overlap. This was particularity evident in the facilitators and solutions category codes, primarily due to the close alignment of the content. Consequently, a second stage of analysis and refinement of the data was conducted which brought together the free text comments under two headings: barriers and facilitators/solutions. This culminated in the formation of facilitators/solutions as depicted in Table 8 and the resultant four emergent themes of: consideration of regulations, issues surrounding structure/process, communication, and reward/recognition.

The following four thematic sections, based on these four emergent themes, will consider the implications of this empirical study in the context of both primary and secondary data (see Table 8) and the development of our proposed HIM approach to interdisciplinary working within UK HE T\&L (Figure 2).

Table 8 near here

\section{Emergent themes and derived enablers of interdisciplinary}

The first thematic section (Regulations) has been identified as a prevailing barrier to embedding interdisciplinarity within HE from the findings of the literature review (Tables 3 and 8) since many professional bodies, funding councils and government bodies have devised policies to drive changes in HE strategy. Indeed, participants from the primary investigation were quite vocal about regulations acting as a barrier. Participant 1 stated:

"I'm a believer that there are things that are impossible to change because of regulations and statutory requirements".

Participants 2 and 3 supported this:

"Barriers are around curricula and especially for quite a lot of accreditation bodies because they have certain topic that they expect you to put in" (participant 2);

"In T\&L some of the biggest barriers are regulatory: they are things like the inflexibility of benchmark statements" (participant 3).

However, participants were also quick to provide possible solutions, to this potential barrier. For example, Participant 3 commented that:

"there is nothing about the way we require them to validate their course which prevents them from doing it but it was just that they were moving too fast basically to 
take the time to stop and think about how do they express this clearly enough to get it through a validation."

Others stated:

"within those professional defined learning outcomes we can get interdisciplinary in there, just extract out elements and learn them through interdisciplinary working" (Participant 2).

This suggests that opportunities for interdisciplinary working do exist and often it is perception of barriers which is a key obstacle (Table 8 - interpretation of restrictions). Indeed, participant 1 stated:

"may be ... we are putting up artificial barriers because we-re tired ... if you challenge or ask, then quite often those barriers disappear".

If this is considered alongside the synthesis of literature (Table 3), where a plethora of authors suggest creating space outside departmental politics to reduce interdepartmental division (Kast et al. 1970, Miller and McCartan 1990; Stember 1991; Jahn et al.'s 2012; McLeish \& Strang 2014), this presents a strong argument for the first enabler of emergent HIM model -POSITIONING (Figure 2). Thus, removing some of the discipline barriers identified by Lawrence and Lorsch (1967) and reducing territories of knowledge (Stember 1991; McLeish \& Strang 2014) to promote a shared ownership (Kast et al. 1970; Stember 1991). Miller and McCartan (1990) suggest best-practice as providing space outside departmental structures. There is a strong argument here for interdisciplinarity in HE to sit outside the formal curriculum to provide optimum scope for buy-in and truly interdisciplinary working outside discipline and course-based constraints and is reflected in POSITIONING (Figure 2).

The second emergent theme of providing a conducive climate (Structure) is also essential for integrating interdisciplinarity into the HE student experience. This is the most prominent theme to emerge out of both literature and the participant interviews, as both a barrier and facilitator (Table 8). This theme relates to the institution providing a congenial atmosphere (Stember, 1991; McLeish and Strang 2014) to foster shared values, a sense of belonging, ownership, recognition and reward and to maximising buy-in through role models and effective leadership as discussed extensively in prior literature (Miller and McCartan 1990; Stember 1991; Jahn et al. 2012; Lawton et al. 2013; McLeish and Strang 2014; and Elsevier 2015). The importance of conducive leadership was highlighted by Participant 4, who recognised that the leadership style:

"... has to be authentic and I think the harder the challenge the more the need for authentic leadership”.

Participant 1 acknowledged that “...innovation is hard, interdisciplinarity is not easy" and, as such, reinforces the argument of McLeish and Strang, (2014) who recognised that leadership has an increasing role to play in synchronizing the efforts of individual members of the team. This is further supported by Participant 3 who commented that:

"a lot, I think, still comes down to staff because you have to have staff who work together effectively so even if your core structures are right if the staff are not ..... 
engaged together then you will still effectively have 2/3 separate experiences taking place within what appears to be a unified interdisciplinary structure."

Participant 4 framed leadership in terms of reward and recognition:

"it's about the way we measure stuff in universities which is about your individual performance as opposed to the collective performance. So you can have a case where somebody maybe hasn't hit their personal targets, but because of their role they have enabled three or four other junior members of staff to do things."

The above extract demonstrates the value of co-creating, championship and the importance of talent management and modelling through authentic leadership.

The importance of this structure theme is demonstrated in our proposed (HIM) model (Figure 2) through three separate enablers: PEOPLE (authentic leadership as highlighted above), ENVIROMENT and FACTORS FOR CONDUCT.

In terms of ENVIROMENT, McLeish and Strang (2014) suggested that interdisciplinary research goes against the grain of many established systems and processes and, for this reason, can be problematic in large organisations. This is reflected in the comments of Participant 6 in terms of infrastructure:

"the biggest barrier in this institution is the way we are silo'd in terms of the schools and the autonomy of the schools over their financial income."

The above resonates with Kast et al. (1970) and Stember's (1991) prior work which identified the significance of poor organisational structures, administrative processes and discipline ownership/divergent discipline goals as barriers to the growth of interdisciplinary within HE. Space - both in terms of physical and mental space - was also a key theme to consider in the model since:

"It comes down to simple logistics like timetabling, space... but I think from a real practical side the idea of timetabling can be a major issue, just because of the scale of the problem of just providing space" (Participant 1 ).

Others, similarly, reflected that space and building facilities matter:

"... it is remarkable what a difference it makes to have people in very close proximity. So having good facilities which are close to each other makes a big difference" (Participant 3).

The final sub-theme - with some spillover into reward was the need to recognise impact beyond research:

"The impact of my actions - and that may not just be REF, but what's the impact of my actions on the university and the student experience and the outside world and my colleagues? I think that is the big emphasis: what difference have I made?" (Participant 3).

"It's really tricky because academics are individuals and they are recognised in their fields as individuals, but where you've got outstanding academics it's always that they are working with other people. They might be the world authority on whatever 
but if you look immediately below you will find that they work very closely with others in collaboration. There are very few people who are there by themselves." (Participant 4)

Combined together, space, resources and infrastructure form the basis of the ENVIROMENT enabler depicted in Figure 2. The final enabler in Figure 2 constructed from the structure theme is FACTORS FOR CONDUCT. This theme is grounded in the works of Kast et al. (1907), Stember (1991) and McLeish and Strang, (2014), who acknowledged six general prerequisites to promote cohesion in interdisciplinary teams: establishing ground rules, explicating and resolving epistemological and methodological differences, understanding bias and nuisance, providing a physical environment to promote cohesion, encouraging intellectual hospitality and respecting and valuing cultural exchanges. This is supported by Participant 1 who commented that:

“... respect of other people's activities, nuances and bias, and an understanding that disagreements or differences of opinion are not a problem, they will always be there and if you stop it being a problem, but see it as something interesting to explore".

It is mooted here that, for disciplines to work together, there needs to be: discipline respect, appreciation, ground rules, understanding of bias and genuine understanding and appreciation of cultural differences.

The third thematic section (reward, recognition and impact) appeared both as a barrier and also facilitator in Table 8 . Five viewpoints have been synthesized: all contribution recognised/measured, role models/champions promoted, incentives, opportunities for impact, and systems to promote a congenial atmosphere, all of which reinforce views highlighted above from the people and environment enablers, as illustrated below:

“...look at that unselfish person and look at how far they have gone'. It's just understanding that working with people will get you much farther down the line than you will ever get by yourself”, (Participant 4).

"... so you do your celebration of the people who are good at it and you reward the people who do the right things and you recognise them and you make sure that there is a very clear articulation of what your criteria for success are so that everybody can understand it." (Participant 3).

"It's talent management; it's role models; it's engagement; it may not be your traditional leadership and it needs to be something more subtle because if you want to get the best out of people they have really got to want to do it" (Participant 4).

It was suggested that there needs to be an exchange of cultures which, as McLeish and Strang (2014) recognised, may be a disconcerting and challenging process, perhaps even resulting in a culture-shock and creating discipline insecurities. However, without this, there will never be a true understanding of being. The leadership challenge, it is proposed, will be to create a consonant system of reward and respect, as opposed to one of mutual bickering (Stember 1991). Miller and McCartan (1990), in support of this, suggested that that interdisciplinary working requires some degree of fiscal autonomy and space to manoeuvre, outside departmental politics. 
Another sub-theme already highlighted above (system to support - infrastructure) is similarly reinforced by primary data analysed under the 'reward/recognition' theme:

“... so putting incentives in place to make it happen because it's only like discipline hopping really but we want it internally to hop over those institutional barriers" (Participant 6).

McLeish and Strang (2014) - endorsing narrative from the expert panel in this study called for universities to review, amongst other things, talent management and systems of targets, incentives and new forms of impact that benefit students, staff and commercial sector.

"I think perhaps the real barrier is to try and get some cultural alignment between the academic sector and the business world" (Participant 5).

The above resonate well with the rationale of interdisciplinarity as a means to solve real world challenges and forms part of the enabler REWARD in the proposed HIM model (Figure 2).

The fourth and final prevailing theme in Table 8 (Communication) emerged directly from the primary data as opposed to literature. It was deemed essential, when developing HIM, that the value, benefits, impact, challenges, barriers and facilitators should be clearly articulated and included as the final enabler - COMMUNICATION.

Participant 3 stated:

"Fundamentally you've got to create a narrative about your desired goal. You've got to tell a story about how things have been in the past and how they are now and what they are going to be like in the future which everybody believes as being credible so it might be that you are emerging from a highly siloed environment and, in which case, your narrative can't pretend that it isn't so you've got to explain how you are moving from that into a world which is much more interdisciplinary".

This view was reinforced by:

"I think it is very much about the benefits and it's about how you engage with academics in the language that they understand" (Participant 4).

"...you need an articulation for the benefits and I think that articulation at the undergraduate level has got to come as a model for the workforce and an appreciation of what it is like in the workforce" (Participant 2).

The final viewpoint articulated from the interviews was that of a need for more direction from the senior management team:

"I think we need more initiatives from the top. It's no good trying to do it bottom up" (Participant 6);

"...if you had a workshop on facilitating interdisciplinarity in the courses then, you won't get many people going to it, but if it somehow becomes something that is more embedded in a general structure then maybe..." (Participant 2). 
The challenges and deficiencies of a non-standardised model are also highlighted below, with several stakeholders and a perceived lack of shared ownership across the HE institution.:

"... we have a group of people, but it is owned by the VC and it's a group that involves teaching, research and enterprise people and so it is not owned by any one particular group and they are tasked, as a group, to come up with a plan." (Participant 4)

This reinforces the need for alignment of people and consideration of group composition, as depicted in Figure 2.

Figure 2 near here

\section{Conclusion and recommendations}

The emergent (HIM) model presented in Figure 2 brings together the six enablers of interdisciplinarity - positioning, people, environment, reward, factors for conduct and communication - derived from a synthesis of literature and expert panel data. This HIM approach positions HE graduates as part of the solution to complex global problems, requiring the integration of interdisciplinary problem-solving into student learning experiences in order to prepare them for the messiness and complexity associated with wicked global challenges. HIM provides a potential solution to effective implementation, based on the findings of extant literature and primary interview data.

It is suggested that interdisciplinarity is best placed outside the curriculum (Enabler 1: positioning), for a number of reasons, including: shared ownership, reducing discipline barriers and removing territories of knowledge. To maximise adoption of an interdisciplinary approach, a collaborative culture of shared values, ownership, recognition and reward should be fostered, with appropriate role models and champions. Authentic leadership (from those who practice interdisciplinarity) and selection of supportive group members are necessary to facilitate this (Enabler 2: people). The provision of physical and mental thinking space and alternative (interdisciplinary working-aware) impact measures, with financial and administrative autonomy, is a further pre-requisite, along with access to technical, physical and human resources; these three-factors are central to successful interdisciplinary working: space, resources and infrastructure (Enabler 3: Environment). The fourth enabler (Reward) is constructed from considering four factors: target measures, talent management, incentives and clarity of impact. The fifth enabler (Factors for Conduct) in based on mutual respect and intellectual fusion, bringing together five areas for consideration: solutions to mitigate against perceived barriers, ontological, epistemological and methodological differences and strategies to encourage cultural exchange. The final enabler (Communication) underpins the value of articulation in terms of benefits, values, impact, challenges, barriers and facilitators of interdisciplinarity, resulting in a clear framework of recognition, reward and open dialogue.

Our proposed HE Interdisciplinarity Model is supported by both the empirical study outlined above and also our comprehensive review of relevant literature. It is argued here that implementation of the model has potential to advise the development of better equipped 
graduates and more effective solutions to complex, messy, global problems likely to be faced in future.

However, it is acknowledged that there is further work to be completed in relation to this HIM approach and its potential validation. The limitations of this study include the small sample size and the purposively selected expert panel. Our study was small scale and exploratory, in order to scope a potential best practice approach. Whilst this generated rich data it cannot be considered statistically representative of the total population and, as such, no claims are made to generalisability. More extensive research is now required in order to validate or suggest amendments to this tentative HIM model. Moreover, although this study considered several different stakeholders, additional consultation with both the student and wider academic body is required. Further embedded research is also required to understand the model's implications within a UK university, requiring commitment from a UK HE institution, its academic staff, student body and also the commercial sector to create a true platform for interdisciplinarity to flourish.

\section{References}

BIS. 2016. "Higher Education: success as a knowledged economy.” UK: Crown copyright. Accessed $18^{\text {th }}$ May 2016. https://www.gov.uk/government/publications/higher-educationsuccess-as-a-knowledge-economy-white-paper.

CBI. 2009. Future fit: Preparing graduates for the world of work. London: CBI.

CIPD. 2016. Attitudes to employability and talent. London: CIPD.

Clark, G. 2014. "Higher education: strength in diversity (speech)." Department for Business, Innovation and Skills. Accessed November 2015.

DC. 2015. "Design council celebrating 70 years." Design Council. Accessed May 2015 http://www.designcouncil.org.uk/about-us/celebrating-70-years.

De Hei, M. S. A., Strijbos, J., Sjoer, E. and Admiraal, W. 2015. "Collaborative learning in higer education: lecturers'practices and beliefs." Research Papers in Education. 30 (2) 232247.

Elsevier. 2015. "A Review of the UK's Interdisciplinary Research using a Citation-based Approach: Report to the UK HE funding bodies and MRC by Elsevier" Accessed 2015. http://www.hefce.ac.uk/media/HEFCE,2014/Content/Pubs/Independentresearch/2015/Review ,of,the,UKs, interdisciplinary,research/2015_interdisc.pdf

Guest, G., Brunce, A. \& Johnson, L. 2006. "How many interviews are enough?:An experiment with data saturation and Variability." Field Methods. (18) 59-82.

Hawley, J. M. 2005. "Border crossing: active and deep learning in a large global consumption class." Clothing and Textiles Research Journal. 23 (4) 307-321. 
Jahn, T., Bergmann, M. and Keil, F. 2012. "Transdisciplinary: Between mainstream and marginalization.” Ecological Economics (79) 1-10.

Jordan, M. E. Robert C. Kleinsasser and Mary F. Roe 2014. "Wicked problems: inescapable wickedity." Journal of Education for Teaching, 40 (4) 415-430, doi:

10.1080/02607476.2014.929381

Kast, F. E., Rosenzweig, J. E. and Stockman, J. W. 1970. "Interdisciplinary Programs in University Setting." The Academy of Management Journal. 13 (3) 311-324.

Lawrence, P. R. and Lorsch, J. W. 1969. "Organisation and environment." Boston: Graduate School of Business Administration, 47-48. USA: Harvard University.

Lincoln, Y.S. \& Guba, E.G. 1985. Naturalistic inquiry. Beverly Hills: Sage.

Marcketti, S. B. and Karpova, E. E. 2014. "Getting ready for the real world: student perspectives on bringing industry collaboration into the classroom." Journal of Family and consumer Science. 104 (1) 27-31.

McLeish, T. and Strang, V. 2014. "Leading interdisciplinary research: transforming the academic landscape." Leadership Foundation for Higher Education.

Miles , M. B. and Huberman, A. M. 1994. "Qualitative data analysis." CA: Thousand Oaks, Sage.

Miller, M. A. and McCartan, A. 1990. "Making the case for new interdisciplinary programs." Change. 22 (33).

Mullins, L.J. 2007. Management and Organisational Behaviour. 8th ed. UK: Prentice Hall.

Patton, M.Q. 2002. Qualitative Research \& Evaluation Methods. $3^{\text {rd }}$ ed. London: Sage.

Power, E. J. 2010. "Devising a product development curriculum to promote industry ready apparel graduates". Paper presented at the The Textile Institute Centenary Conference. Manchester UK.

RAE. 2012. "Educating engineers to drive the innovation economy." The Royal Academy of Engineering. Accessed Sep 2015. http://www.raeng.org.uk/publications/reports/innovationeconomy-2012. 1-30.

Reeves, T. C and Hedberg, J. C. 2003. Interactive learning systems evaluation. US: Education Technology Publications.

Robson, C. 2011. Real World Research. $3^{\text {rd }}$ ed. Chichester: John Wiley.

Saunders, M, N., K. 2012. Choosing Research Participants. In Symon, G. and Cassell, C. Qualitative Organizational Research. 2012. London: Sage.

Stember, M. 1991. "Advancing the social sciences through the interdisciplinary enterprise." The Social Science Journal. 28 (1) 1-14. 
Torrington, D., Hall, L., Taylor, S. \& Atkinson, C. 2014. Human Resource Management . 9th Ed. US: Pearson.

United Nations. 2015. Global Sustainable Development Report, 2015 Edition: Advance Unedited Version. Accessed 2017. https://sustainabledevelopment.un.org/content/documents/1758GSDR\%202015\%20Advance $\%$ 20Unedited $\% 20$ Version.pdf.

Vitae, 2015. "Ethical principles for research." Accessed Oct 2015. https://www.vitae.ac.uk/researchers-professional-development/research-governance-andorganisation/professional-conduct/ethics-in-research/ethical-principles-for-research

Walsh, L. and Kahn, P. 2010. “Collaborative working in Higher Education.” UK: Routledge.

Watson, D. 2014. "The Question of Conscience: Higher Education and Personal Responsibility.” London: IOE Press. 


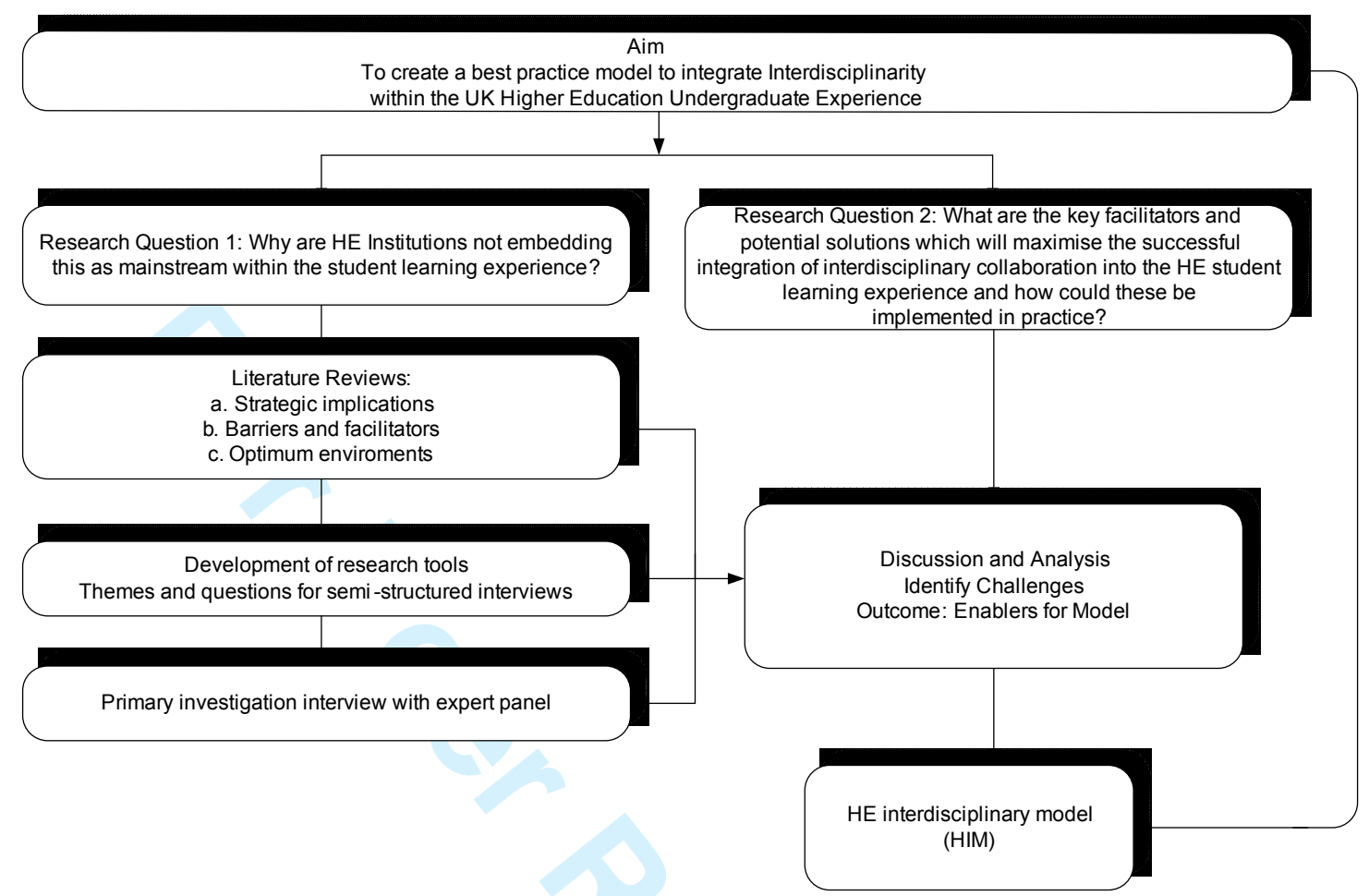

Figure 1 - Framework for research

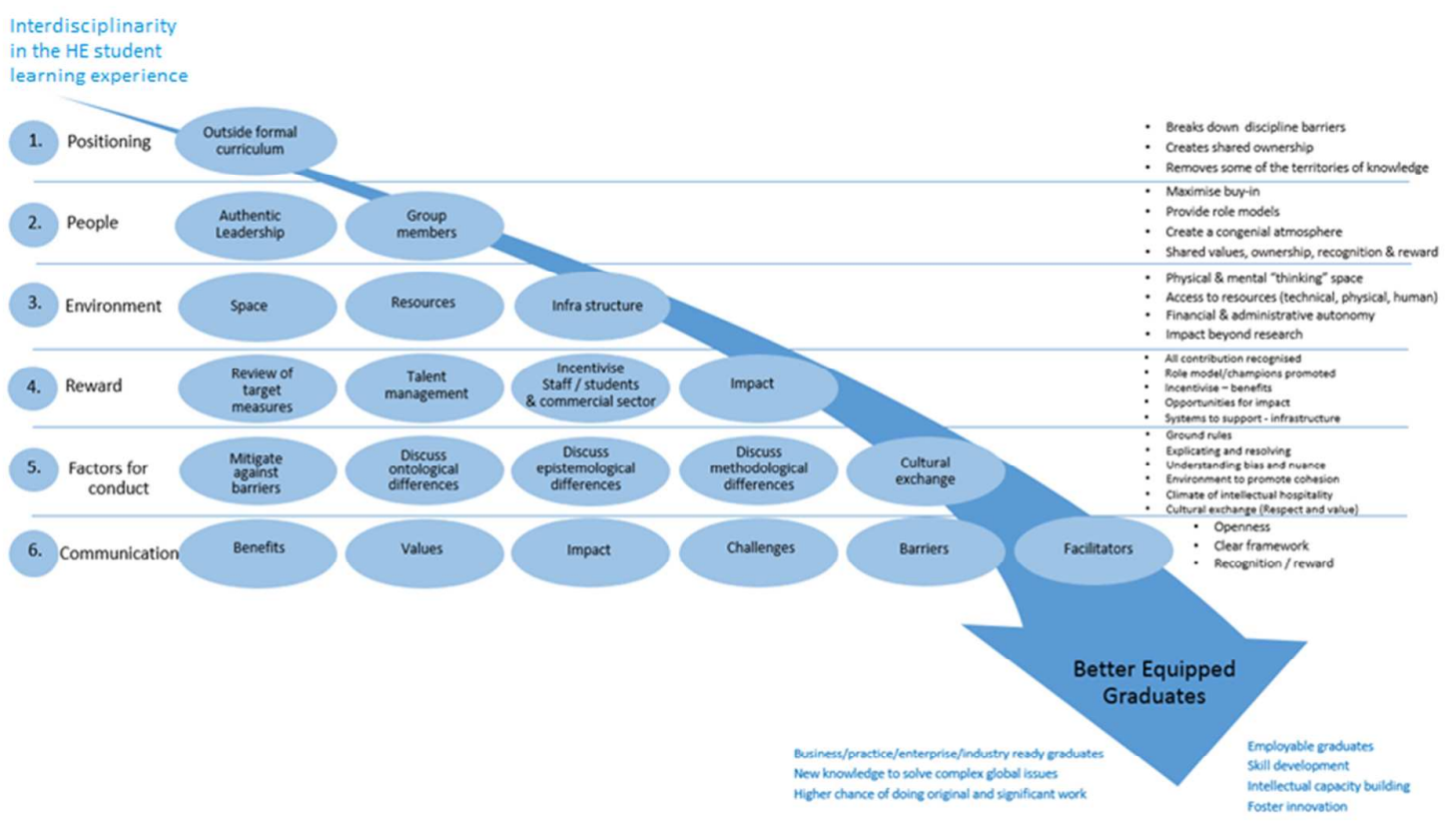

Figure 2 - Model of best practice to integrate interdisciplinarity into the HE UG experience. 
Table 1 - Criteria for initial sampling frame

\begin{tabular}{lll}
\hline Rank & Criteria & Justification for sampling \\
\hline $\mathbf{1}$ & $\begin{array}{l}\text { Knowledge of enterprise of collaborative nature } \\
\text { (Expert) }\end{array}$ & $\begin{array}{l}\text { Been directly involved with industry collaborative } \\
\text { projects within Higher Education }\end{array}$ \\
$\mathbf{2}$ & Working within or a stakeholder in UK Higher Education & $\begin{array}{l}\text { Employed or working with Higher } \\
\text { Education and employability agenda }\end{array}$ \\
$\mathbf{3}$ & $\begin{array}{l}\text { Involved with projects within Higher Education that promote } \\
\text { interdisciplinarity in teaching, learning \& enterprise }\end{array}$ & Expertise/experience of enterprise education policy \\
$\mathbf{4}$ & $\begin{array}{l}\text { Located within close proximity to the researcher } \\
\text { (demographics) }\end{array}$ & $\begin{array}{l}\text { Promixmity to researcher (30 miles radius) due to time } \\
\text { constraints }\end{array}$ \\
$\mathbf{5}$ & Balanced quota (3 female / 3 male) & Gender balance as it may be relevant to perception \\
\hline
\end{tabular}

Table 2 - Primary data design and analysis

\begin{tabular}{lcl}
\hline Analytical strategy & Study Approach \\
\hline Research Design & - & Devise questions based on knowledge gaps established from literature \\
& - & Condense questions and group under $4 / 5$ section headings \\
Data collection & - & Re-focus main and sub-questions \\
& - & Arrange interviews \\
& - & Conduct interviews (audio record) \\
- & Transcribe interviews \\
Data display & - & Check and refine transcripts \\
& - & Align transcript data under section headings and questions \\
Data reduction & - & Remove unrelated data \\
& - & Odd column headings to ensure data could be tracked to specific question and \\
Open thematic coding & & participant \\
Analysis & - & Split each sentence or paragraph into a specific cell - further reduce data as \\
& & appropriate and provide each cell with a unique ID code \\
& - & 4 codes were used to analyse data - open, axial, general and relationship/ordering \\
& - & Selective coding was used to bring in extracts to support emerging themes. \\
\hline
\end{tabular}

\section{Table 3 - Synthesis of Barriers and Facilitators from literature}

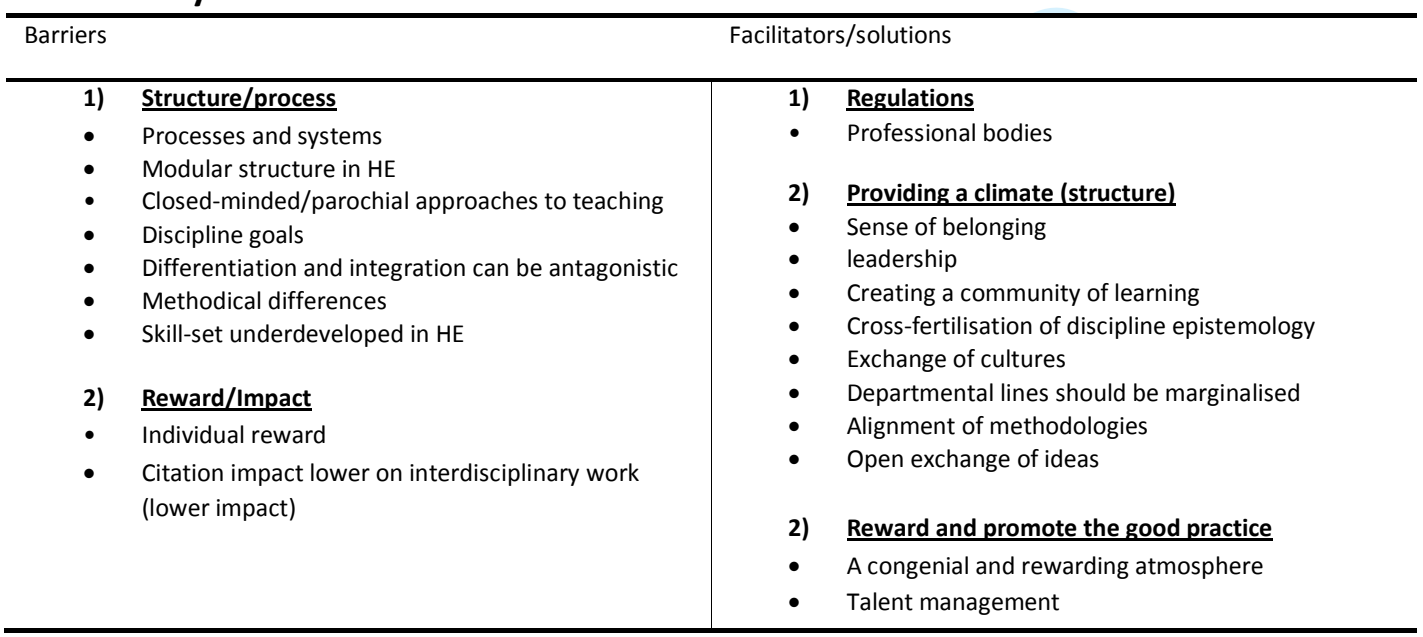


Table 4 - Category codes: barriers, facilitators and solutions

\begin{tabular}{|c|c|c|c|c|c|c|}
\hline \multirow{6}{*}{ 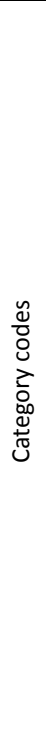 } & \multirow[b]{2}{*}{$\frac{n}{\frac{N}{2}}$} & Regulation (5) & PRSB (3) & Staff (2) & Resources (1) & \\
\hline & & $\begin{array}{l}\text { perceived barriers } \\
\text { perceived barriers } \\
\text { learning outcomes } \\
\text { learning outcomes } \\
\text { policy/ environment }\end{array}$ & $\begin{array}{l}\text { specific curricula } \\
\text { specific curricula } \\
\text { specific curricula }\end{array}$ & $\begin{array}{l}\text { integration } \\
\text { perceived barriers }\end{array}$ & logistics & \\
\hline & \multirow[b]{2}{*}{ 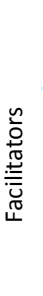 } & Culture (5) & Staff (4) & Recognition (3) & Structure (1) & $\begin{array}{l}\text { other (4) - policy/electives/ } \\
\text { environment/impact }\end{array}$ \\
\hline & & $\begin{array}{l}\text { commercial } \\
\text { alignment } \\
\text { commercial } \\
\text { alignment } \\
\text { mind-set } \\
\text { reward/recognition } \\
\text { Targets/reward }\end{array}$ & $\begin{array}{l}\text { aspirational learning } \\
\text { co-creation of knowledge } \\
\text { culture } \\
\text { culture }\end{array}$ & $\begin{array}{l}\text { impact/individual } \\
\text { reward } \\
\text { impact/individual } \\
\text { reward } \\
\text { Targets /reward }\end{array}$ & $\begin{array}{l}\text { faculty silos } \\
\text { faculty Silos }\end{array}$ & $\begin{array}{l}\text { driver } \\
\text { restrictions } \\
\text { facilities } \\
\text { REF }\end{array}$ \\
\hline & \multirow[b]{2}{*}{ 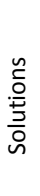 } & Communication (4) & Structure (4) & $\begin{array}{l}\text { Culture change } \\
\text { (2) }\end{array}$ & & \\
\hline & & $\begin{array}{l}\text { narrative } \\
\text { narrative } \\
\text { narrative } \\
\text { narrative }\end{array}$ & $\begin{array}{l}\text { embedded } \\
\text { models } \\
\text { models/top-down } \\
\text { models/top-down }\end{array}$ & $\begin{array}{l}\text { role models } \\
\text { role models }\end{array}$ & & \\
\hline & & en coc & l codes & & & \\
\hline
\end{tabular}

Table 5 - Open codes: barriers

\begin{tabular}{|c|c|c|}
\hline 突 & $\begin{array}{l}\text { Open and } \\
\text { Axial codes }\end{array}$ & Representative Data (Extracts) \\
\hline \multirow{9}{*}{ 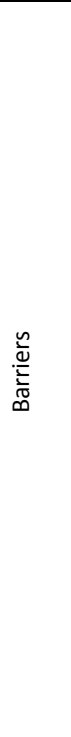 } & $\begin{array}{l}\text { Regulations } \\
\text { (Learning }\end{array}$ & $\begin{array}{l}\text {-if you are clear enough on what your intended learning outcomes are and if you articulate them effectively then } \\
\text { they can be interdisciplinary. (P-003, ID135) }\end{array}$ \\
\hline & $\begin{array}{l}\text { outcomes, } \\
\text { perceived } \\
\text { barriers, }\end{array}$ & $\begin{array}{l}\text {-there is nothing about the way we require them to validate their course which prevents them from doing it but } \\
\text { it was just that they were moving too fast basically to take the time to stop and think about how do they express } \\
\text { this clearly enough to get it through a validation. ( } P-003, I D \text { 136) }\end{array}$ \\
\hline & $\begin{array}{l}\text { policy, } \\
\text { environment) }\end{array}$ & $\begin{array}{l}\text { - within those professional defined learning outcomes we can get interdisciplinary in there, just extract out } \\
\text { elements and learn them through interdisciplinary working, but I think from a real practical side the idea of } \\
\text { timetabling can be a major issue, just because of the scale of the problem of just providing space. (P-001, ID 124) } \\
\text {-Innovation is hard, interdisciplinary is not easy and it may be that we are putting up artificial barriers because } \\
\text { we-re tired. (P-001, ID 151) }\end{array}$ \\
\hline & & $\begin{array}{l}\text {-There is the next stage where there are things that an anomaly ...you can't do thing but if you challenge or ask } \\
\text { then quite often those barriers disappear. (P-001, ID 150) }\end{array}$ \\
\hline & & $\begin{array}{l}-I^{\prime} m \text { a believer that there are things that are impossible to change because of regulations and statutory } \\
\text { requirements, and the technicalities of space (laws of physics) and those are the kind of things that much as you } \\
\text { might want to work in a space you just can't. (P-001, ID 129) }\end{array}$ \\
\hline & $\begin{array}{l}\text { PSRB } \\
\text { (Specific }\end{array}$ & $\begin{array}{l}\text {-Barriers are around curricula and especially for quite a lot of accreditation bodies because they have certain } \\
\text { topic that they expect you to put in . (P-002-ID129) }\end{array}$ \\
\hline & curricula) & $\begin{array}{l}\text {-In teaching and learning some of the biggest barriers are regulatory: they are things like the inflexibility of } \\
\text { benchmark statements. (P-003, ID 132) }\end{array}$ \\
\hline & Other & -Other barriers are general resistance from the staff about change. (P-002, ID130) \\
\hline & $\begin{array}{l}\text { (Staff, } \\
\text { resources) }\end{array}$ & $\begin{array}{l}\text { - it comes down to simple logistics like timetabling, space, the need to work within professional defined learning } \\
\text { outcomes. (P-001, ID124) }\end{array}$ \\
\hline
\end{tabular}


Table 6 - Open codes: facilitators

\section{Table 7 - Open codes: solutions data}

\begin{tabular}{|c|c|c|}
\hline 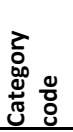 & $\begin{array}{l}\text { Open and Axial } \\
\text { codes }\end{array}$ & Representative Data (Extracts) \\
\hline \multirow{5}{*}{ 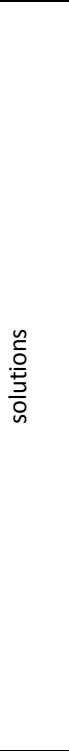 } & $\begin{array}{l}\text { Communication } \\
\text { (narrative) }\end{array}$ & $\begin{array}{l}\text { - You need an articulation for the benefits and I think that articulation at the undergraduate level has got to } \\
\text { come as a model for the workforce and an appreciation of what it is like in the workforce. (P-002, ID131). } \\
\text {-Fundamentally you've got to create a narrative about your desired goal. You've got to tell a story about how } \\
\text { things have been in the past and how they are now and what they are going to be like in the future which } \\
\text { everybody believes as being credible so it might be that you are emerging from a highly siloed environment } \\
\text { and, in which case, your narrative can't pretend that it isn't so you've got to explain how you are moving from } \\
\text { that into a world which is much more interdisciplinary. (P003, ID154) } \\
\text {-I think it is very much about the benefits and it's about how you engage with academics in the language that } \\
\text { they understand. (P-004, ID157) }\end{array}$ \\
\hline & Structure & -I think we need more initiatives from the top. It's no good trying to do it bottom up. (P-006, ID160) \\
\hline & (models) & $\begin{array}{l}\text {-we have a group of people but it is owned by the VC and it's a group that involves teaching, research and } \\
\text { enterprise people and so it is not owned by any one particular group and they are tasked, as a group, to come } \\
\text { up with a plan. (P-004, ID162) }\end{array}$ \\
\hline & & $\begin{array}{l}\text {-as enablers, we have to give them the opportunity and almost force the opportunities onto people because } \\
\text { they don't , if you had a workshop on facilitating interdisciplinarity in the courses then, you won't get many } \\
\text { people going to it, but if it somehow becomes something that is more embedded in a general structure then } \\
\text { maybe. But in terms of cooperation I think people would cooperate and it's a question of persuasion versus } \\
\text { coercion, isn't it? (P-002, ID153) }\end{array}$ \\
\hline & $\begin{array}{l}\text { Culture Change } \\
\text { (role models) }\end{array}$ & $\begin{array}{l}\text {-So you do your celebration of the people who are good at it and you reward the people who do the right } \\
\text { things and you recognise them and you make sure that there is a very clear articulation of what your criteria } \\
\text { for success are so that everybody can understand it. (P-003, ID155) } \\
\text {-'look at that unselfish person and look at how far they have gone'. It's just understanding that working with } \\
\text { people will get you much farther down the line than you will ever get by yourself. (P004, ID148) }\end{array}$ \\
\hline
\end{tabular}


Table 8 - Synthesis of primary and secondary data

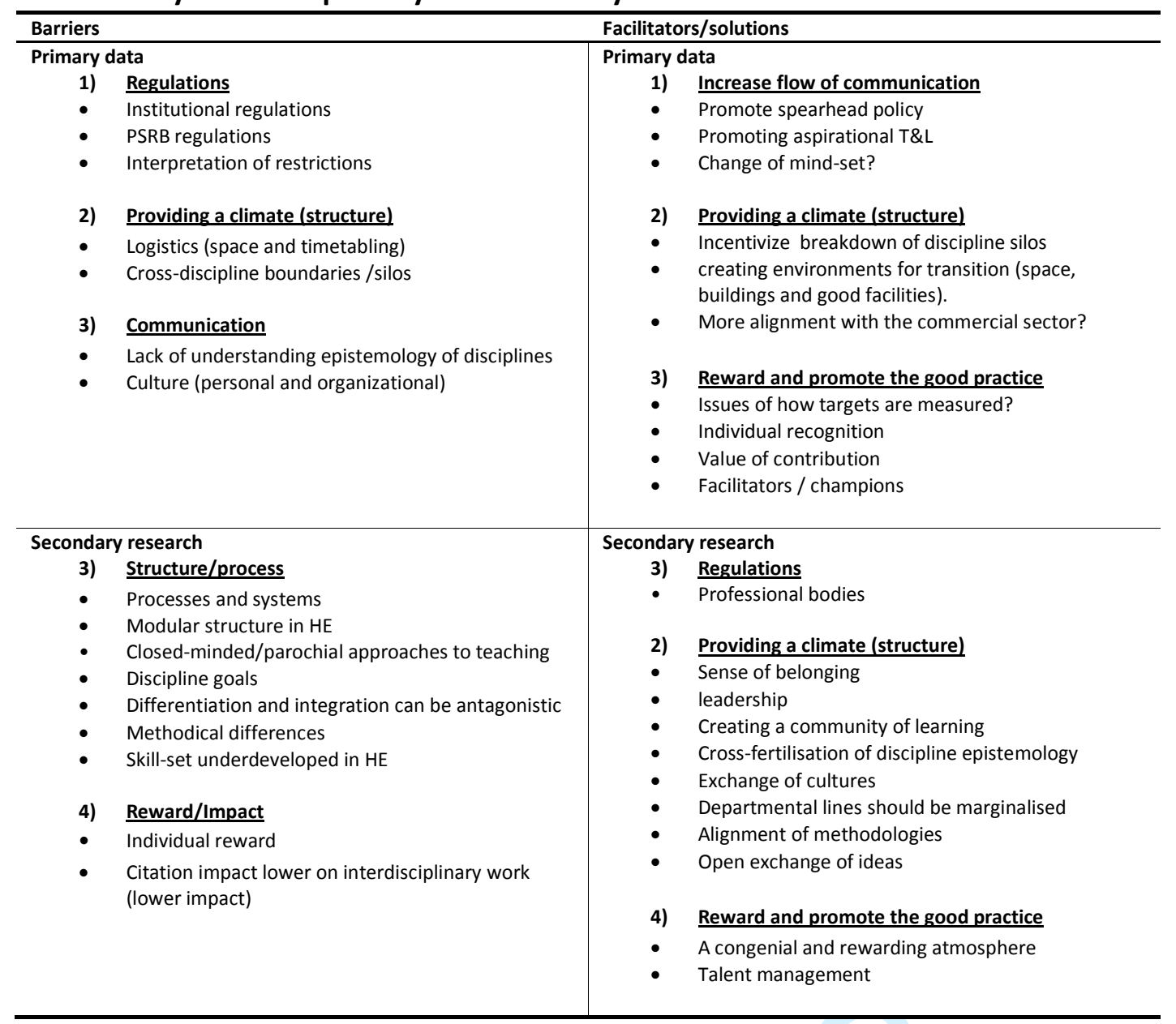

